are not thrown about on their seats during heavy braking and tight turns. Clearly all belts must allow the driver easy access to all the control systems of the car.

Can belts cause injury or increase the severity of injury? Bruising and sometimes minor fractures of the ribs may be produced by great forces transmitted from the vehicle to the driver wearing a belt, but the injuries would have been more severe had the occupant been flung against any of the many projections within the vehicle. ${ }^{6}$ There have been at least two horror stories of belts causing serious injuries. The first was a "whiplash" fracture-dislocation of the cervical spine with damage to the spinal cord. This injury was proved to be caused by the chin of a front-seat passenger hitting the dashboard, since the particular type of belt worn allowed free forward movement of the trunk on the hips. The second incident was the decapitation of a person wearing a diagonal pillar-mounted belt. This occurred when his head was pushed through an open door, which closed on his neck as the car rolled over on to its side. ${ }^{4}$ There have been no substantiated cases where a seat-belt caused severe injury or increased the severity of injury. Inevitably, however, in some situations, particularly in collisions at high speeds, seat-belts or the bodywork of the car will fail to protect the occupants from serious or even fatal injuries. In this connexion Lindgren and Warg's study is informative, since, from an analysis of 2,109 accidents in Sweden from 1958 to 1961 they show that most accidents happened at low speeds-in almost $90 \%$ below 30 m.p.h. ${ }^{3}$ Two-thirds of the 923 persons injured and eight of the 15 killed were involved in accidents at speeds below 30 m.p.h.

In 1954 Colonel J. P. Stapp of the United States Medical Corps rode in a rocket-propelled sledge fitted with special restraining harness and submitted himself to a deceleration force of approximately $50 \mathrm{~g}$. This is probably near the upper limit of tolerable deceleration and beyond what the materials used in the modern car would stand without damage. Moreover this deceleration was the equivalent of a crash at 60 m.p.h. into a rigid barrier, and most crashes are much less severe. Protective devices to endure a force of up to 20 or $30 \mathrm{~g}$. are within the range of available materials and, as Stapp's experiments have shown, cause no more than momentary dizziness to the passengers when they are exposed to sudden deceleration.

On this evidence it is surprising that in Great Britain no more than $5 \%$ of vehicles are now fitted with safety-belts; nor are the medical profession setting an example. Perhaps the most effective advertisement for safety-belts would be, "My doctor wears and recommends them."

\section{Pathogenesis of Dissecting Aneurysm}

Dissecting aneurysm usually affects the aorta but it may also extend into its branches, and occasionally primary dissection occurs in pulmonary, renal, and other muscular arteries. ${ }^{12}$ Blood enters the area to be dissected through an intimal tear which is usually situated in the region of an atherosclerotic plaque in the ascending aorta. ${ }^{34}$ The possibility that the intima might be torn after intramural haemorrhage from the vasa vasorum is unlikely, since this would not lead to sufficient pressure to dissect the media and compress the lumen of the aorta. F. C. Bauer and E. F. Hirsch ${ }^{5}$ have reported a single instance in which fatal dissection of the aorta was not accompanied by haemorrhage in the vessel wall. This suggests that spontaneous dissection can sometimes result from longitudinal shearing strain (or " viscous drag ") 6 on the aortic wall.

H. Braunstein ${ }^{4}$ suggests that the ascending aorta is most frequently affected because it is often dilated owing to atrophy of its media, and because almost all patients with dissecting aneurysm are hypertensive. This dilatation of the ascending aorta causes increased lateral tension to be thrown on its wall.

O. Gsell ${ }^{7}$ and J. Erdheim ${ }^{8}$ were the first to describe the association of dissecting aneurysm with medial necrosis and cystic accumulation of mucoid material, which in histological sections stains metachromatically-i.e., basic dyes stain it a different colour than the surrounding tissues. The importance of this material in the pathogenesis of dissecting aneurysm may have been over-emphasized, for it also accumulates or becomes unmasked from the tissues during the development of atherosclerosis. ${ }^{9-11}$ The metachromatic material in the aorta in dissecting aneurysm has been shown by biochemical ${ }^{12}$ and histochemical means ${ }^{13}{ }^{14}$ to be chondroitin sulphate $C$, though the total amount of mucopolysaccharide in the aortic wall remains practically constant.

Dissection usually occurs at the junction of the middle and outer thirds of the aortic media. ${ }^{3415}$ This zone is the vascular watershed between the territory supplied by the vasa vasorum and that nourished directly by diffusion from the blood in the aorta. ${ }^{16} 17$ This middle layer would therefore be expected to be the first to suffer any ischaemic damage in ageing, and indeed the muscle fibres in this layer have been shown to degenerate and to lose enzyme activity as early as the third or fourth decade. ${ }^{18}$ In rabbits necrosis of the media in the aorta has been produced by repeated injection of adrenaline, ${ }^{19}$ while in dogs stripping the vasa vasorum from the aorta has been shown to lead to acute necrosis of the outer zone of the media. ${ }^{20}$

Severe loss of smooth muscle in the media is a feature common to both dissecting aneurysms ${ }^{21}$ and senile aortas. ${ }^{18} 22$ Though H. Braunstein ${ }^{4}$ doubts whether necrosis of the media is important in the pathogenesis of dissecting aneurysm, this might lead to a loss of cohesion between the elastic fibres in the aorta and so determine the layer at which dissection begins. Erdheim's ${ }^{8}$ cystic necrosis of the media may not be a specific disease and probably most elderly subjects develop varying degrees of localized ischaemic damage in the aortic media. 2 Henry, L., and Burke, W. D., Angiology, 1963, 14, 269.

- Gore, I., and Seiwert, V. J., Arch. Path., 1963.

s Bauer, F C. and Hirsch, E. F., Arch. Path., 1955, 59, 219

McDonald, D A. Blood Flow in Arteries, 1960. Arnold, London.

Gsell, O., Arch. path. Anat., 1928, 270, 1.

Gsell, O., Arch. path. Anat, 1928,

Trdheim, J., ibid., 1930, 276, 187. 190 , 29, 871.

Zugibe, F. T., Ұ. Histochem. Cytochem., 1962, 10, 448.

and Brown, K. D., Circulat. Res., 1960, 8, 287.

Manley, G., and Kent, P. W., Brit. F. exp. Path., 1963, 44, 635

is Raekallio, J., Arch. Path., 1958, 66, 733.

Braunstein, H., ibid., 1960, 69, 617.

Cleland, J. B., Med. 7. Aust., 1951, 2, 399.

16 Kirk J. E. and Larsen, T. S. 7. Gerontol., 1955, 10, 288.

Woerner, C. A., in The Arterial Wall, ed. by A. I. Lansing, 1959, p. 1 Williams and Wilkins, Baltimore.

. Adams, C. W. M., Bayliss, O. B., and Ibrahim, M. Z. M., 7. Path. Bact., 1963, 86, 421 .

Josué, O., C.R. Soc. Biol. (Paris), 1903, 55, 1374

Schlichter, J. G., Arch. Path., 1946, 42, 182.

Rottino, A., ibid., 1939, 28, 1.

22 - ibid., 1939, 28.377.

${ }^{23}$ Macleod, M., and Williams, A. W., ibid., 1956, 61, 143.

24 Bachhuber, T. E., and Lalich, J. J., ibid., 1955, 59, 247.

2s Wawzonek, S. Ponseti, I. V., Shepard, R. S., and Wiedermann, L. G., Science, $1955,121,63$.

${ }_{26}$ Levene, C. I., Brit. F. exp. Path., 1961, 42, 89. 
Blood from the lumen penetrates the outer media only rarely, but it is able to produce a dissection if an area of medial necrosis is present.

In younger patients dissecting aortic aneurysm is associated with destruction of the elastic tissue in the media rather than the muscle ${ }^{34}$; developmental abnormalities are also found in these patients. Destruction of the medial elastic layer, dissecting aneurysms, and rupture of the aorta are also features of Marfan's syndrome ${ }^{423}$-a genetically determined abnormality of connective tissue-and of experimental lathyrism induced by ingestion of sweet pea (Lathyrus odoratus) ${ }^{24}$ or $\beta$-aminopropionitrile. ${ }^{25} 28$

\section{Productive Life}

Confronted with the startling productivity of his own species, man is becoming worried about the productivity of the plant and animal life on which he depends for food. His use and abuse of chemical sprays to increase the food supply needs to be based on a clearer knowledge of their effects, as was stressed in the previous issue of this journal. ${ }^{1}$ The point was aptly illustrated last week by reports of the death of millions of birds and fishes in the Mississippi basin from pesticides sprayed on the crops there, ${ }^{2}$ and the British Government has now prohibited the use of certain insecticides after this and next season. ${ }^{3}$

Thus a project to study " the biological basis of productivity and human welfare" is timely. It is being launched as an International Biological Programme, and deserves the warm support that its predecessor the International Geophysical Year attracted. The International Council of Scientific Unions has sponsored both, but owing to the longer period needed to collect biological data a programme of several years is being drawn up instead of the single year devoted to geophysics. The Royal Society has set up a British National Committee to co-ordinate the United Kingdom's contribution with that of the Programme as a whole. The chairman of the committee is Professor A. A. Miles, F.R.S., who is biological secretary of the Royal Society and director of the Lister Institute.

Three sections of the Programme are to be devoted to studying the productivity of terrestrial, fresh-water, and marine communities, while the fourth and fifth sections are concerned with human adaptability and the use and management of biological resources. The general intention is that the studies undertaken should be of a kind requiring international co-operation for their completion. A meeting to formulate projects in more detail will be held next July in Paris.

In man's exceedingly varied relationships with the environment greed has too often led to the creation of dust-bowls, the destruction of fisheries, even the extinction of many whole species in recent decades. Lately pollution of the land by smoke and the sea by oil have created problems not yet fully understood, let alone solved. Thus an important feature of the International Biological Programme will be research into aquatic and terrestrial organisms which enter into the production of man's food. Workers in the section on human adaptability hope to study, among other things, the physiology of tolerance to extremes of cold, heat, and high altitude;

\footnotetext{
1 Brit. med. F., 1964, 1, 790.

The Times, 23 March 1964.

S See page 919.
}

characteristics of special occupations such as fishermen and lumberjacks ; and the genetics of different populations.

Inquiries about the International Biological Programme may be addressed to Dr. R. W. J. Keay, Deputy Executive Secretary, Royal Society, Burlington House, London, W.1.

\section{Curiosity and Common Sense}

Curiosity is supposed to have killed the cat, presumably because a cat has no common sense. Marry the two qualities, and great inventiveness is the result. John Graunt combined a restless curiosity about the relationship between births and deaths, the growth of population, the prevalence of different diseases, and the length of life with a degree of common sense which forbade him to accept figures at their face value. His consequent Natural and Political Observations on Bills of Mortality are regarded as laying the foundation of British demography. The tercentenary of their publication in 1662 was commemorated in 1962 by the Royal Society (Graunt was one of their first Fellows), which arranged a series of discussions on demographic subjects, contributed to by leading demographers from many countries. The transactions of the meeting, recently published, ${ }^{1}$ will be of interest to many medical men.

The meetings were opened by Professor David Glass with a refreshing review of John Graunt's life and work. Graunt's examination of the probable extent of under-reporting of plague and of syphilis bears a notably modern stamp in the critical apparatus he deployed. So also does his approach to another problem which worried him-Was rickets a new disease or a new 'name for an old disease? As Dr. Ian Sutherland said in discussion, "One of the most striking aspects of Graunt's book to the present-day reader is the sure-footed way in which he picked a path through a mass of untidy numerical data, apparently instinctively keeping clear of that which was unanalysable and extracting the maximum of information from the rest. He seems too to have had an intuitive appreciation of just how much interpretation his findings would stand and took care to go no further."

From the simple beginnings of John Graunt methods of mortality analysis have developed in refinement and variety, as Dr. Bernard Benjamin showed in a historical review of mortality measurement. "Graunt provided a new idea ; an idea pregnant with developments certainly not all of which he can have foreseen. The idea which he presented was of a group of births followed through life and gradually reduced in number by deaths ... it represented a tremendous leap forward from the simple death rate to a new and graphic method of representing the age pattern of mortality."

Discussing current trends in public health Professor J. N. Morris showed how the disciplined curiosity of Graunt is applied to the problems of modern epidemiology. These include the persisting social gradient in infant mortality, social disturbance in adolescence, and chronic illness in relation to social factors. Graunt also concerned himself with fertility and marriage, and so did the Royal Society meetings. Professor L. S. Penrose, F.R.S., discussed powerful genetical forces which produce differences in fertility between individuals. Dr. A. S. Parkes, F.R.S., drew attention to the paradoxical situation " in which time and money is being

\footnotetext{
1 Proc. roy. Soc. B, 1963, 159, 1-255.
} 